\title{
Antioxidant Properties of Phenylpropanoids
}

\author{
Veronika Hýsková*, Helena Ryšlavá \\ Department of Biochemistry, Faculty of Science, Charles University, Hlavova 2030, Czech Republic
}

Phenylpropanoids (or phenolic compounds) are a large class of plant secondary metabolites usually consisting of six-carbon aromatic phenyl group and three-carbon propane side chain. Flavonoids, monolignols (precursors of lignin), and phenolic acids are three most common groups, which can be found almost in all plants [1]. These compounds have important functions in plants as antibiotics, natural pesticides, signal molecules for the interaction of symbiotic rhizobia with plant roots, attractants for pollinators, protective agents against UV light, and structural material for plant stability [2]. On the other hand, many positive effects of phenolic compounds on human health were found. Phenolic compounds are the most widespread dietary antioxidants. The trend to view many foods not only as sustenance but also a medicine, so called functional food, is increasing [3]. All phenolic compounds as they possess aromatic ring(s) linked to hydroxyl groups are potent antioxidants with usually high redox potentials [4]. High redox potentials allow them to act as reducing agents, hydrogen donors, radical scavengers, and singlet oxygen quenchers. In addition, they have a metal-chelating ability [5]. Therefore, phenolic compounds play an important role in removing of harmful by-products (reactive oxygen species ROS) formed during normal aerobic cell respiration and especially in oxidative stress under pathological conditions [58]. ROS and free radicals-induced oxidation of proteins, lipids, and even DNA lead to the aging and is in relationship with many serious diseases. Massive studies revealed that many widespread chronic diseases such as cardiovascular diseases, type II diabetes, and various cancers can be reduced by taking phenylpropanoids $[1,9]$.

Flavonoids in tea, soybean, chocolate, grape, and biologically active ingredients in various medicinal plants, such as Ginkgo biloba, are well known antioxidants [1]. But simple phenolic compounds are potent antioxidants too. For example, antioxidant potential of chlorogenic acid is probably more accessible than that of many flavonoids [3]. Chlorogenic acids are a family of soluble esters of hydroxycinnamic acids and quinic acid with beneficial health effects for both plants and animals [4,10]. For instance, in tobacco plants viral [11] or bacterial infection [10] leads to increase of several phenolic acids. Chlorogenic acids accumulate in very high levels in coffee beans and poplar, when they act as feeding deterrent [12]. Chlorogenic acid is also the major soluble phenolics in Solanaceous species such as potato, tomato, and eggplant. It is important dietary bioactive present also in other vegetable, fruit, and herbs. Small intestine esterases hydrolyses chlorogenic acids into caffeic and quinic acids, moreover microbial enzymes of large intestine could produce other phenylpropanoid derivatives $[3,4]$. Caffeic acid has high antioxidant capacity too [3]. The pharmaceutical research focuses on chlorogenic acid as a potential weight loss supplement and compound with anti-diabetic, anti-inflammatory, and antiatherosclerotic compound $[4,12]$.

In addition to fruits and vegetables, herbs are an abundant source of phenolic compounds. These can be simply administered in the form of hot water extracts i.e., teas. Our latest project comparing 15 herbal plants showed that the extracts of all the tested potential medicinal plants possessed antioxidant capacity, which was correlated with the content of total phenolic compounds. Thus, using these plant species, especially Agrimonia eupatoria L., Origanum vulgare L., and Mentha $\times$ piperita L. in the form of herbal tea or spices could protect the organism from ROS that has arisen in the metabolism or during pathological events [5].

Beside the quantitative content of phenolic compounds, the qualitative content is also important. The interaction among plant metabolites can be synergistic, antagonistic or additive and the effect of mutual action can lead to the changed final effect [13]. Depending on reaction partner, the antioxidant may also exhibit pro-oxidant properties [4]. Moreover, various factors that are external to the dietary source can also affect bioavailability of phenolic compounds, e.g., milk added to coffee beverage may increase bioavailability of chlorogenic acid [4].

\section{REFERENCES}

1. Deng Y, Lu S. Biosynthesis and regulation of phenylpropanoids in plants. Crit Rev Plant Sci. 36: 2017;257-290.

2. Heldt HW, Piechulla B. Plant Biochemistry (4thedn), Elsevier Academic Press. 2010.

3. Niggeweg R, Michael AJ, Martin C. Engineering plants with increased levels of the antioxidant chlorogenic acid. Nat Biotechnol. 2004;22:746-754.

4. Liang N, Kitts DD. Role of chlorogenic acids in controlling oxidative and inflammatory stress conditions. Nutrients. 2015;8(1):1-20.

5. Tupec M, Hýsková V, Bělonožníková K, Hraníček J, Červený V, Ryšlavá H. Characterization of some potential medicinal plants from Central Europe by their antioxidant capacity and the presence of metal elements. Food Biosci. 2017;20:43-50.

6. Boxin O, Huang D, Hampsch-Woodill M, Flanagan JA, Deemer EK. Analysis of antioxidant activities of common vegetables employing

Correspondence to: Dr. Veronika Hyskova, Department of Biochemistry, Faculty of Science, Charles University, Hlavova 2030, Czech Republic, Tel: 221951344; E-mail: veronika.hyskova@natur.cuni.cz

Received: May 23, 2019; Accepted: July 03, 2019; Published: July 10, 2019

Citation: Hýsková V, Ryšlavá H (2019) Antioxidant Properties of Phenylpropanoids. Biochem Anal Biochem 8:e171. doi: 10.35248/2161-1009.19.8.e171.

Copyright: (C) 2019 Hýsková V, et al. This is an open-access article distributed under the terms of the Creative Commons Attribution License, which permits unrestricted use, distribution, and reproduction in any medium, provided the original author and source are credited. 
oxygen radical absorbance capacity (ORAC) and ferric reducing antioxidant power (FRAP) assays: A comparative study. J Agric Food Chem. 2002;50:3122-3128.

7. Song JH, Han YM, Kim WH, Park JM, Jeong M, Go EJ, et al. Oxidative stress from reflux esophagitis to esophageal cancer: the alleviation with antioxidants. Free Radic Res. 2016;50:1071-1079.

8. Tramutola A, Lanzillotta C, Perluigi M, Butterfield DA. Oxidative stress, protein modification and Alzheimer disease. Brain Res Bull. 2016;133:88-96.

9. Hamzaa RG, Osman NN. Using of Coffee and Cardamom Mixture to Ameliorate Oxidative Stress Induced in $\gamma$-irradiated Rats. Biochem Anal Biochem. 2012;113:2161-1009.
10. Baker CJ, Mock NM, Averyanov AA. A simplified technique to detect variations of leaf chlorogenic acid levels between and within plants caused by maturation or biological stress. Physiol Mol Plant Pathol. 2017;98:97-103.

11. Spoustová P, Hýsková V, Müller $K$, Schnablová R, Ryšlavá $H$, Čřrovská $\mathrm{N}$, et al. Tobacco susceptibility to Potato virus $\mathrm{Y}^{\mathrm{NTN}}$ infection is affected by grafting and endogenous cytokinin content. Plant Sci. 2015;235:25-36.

12. Guo J, Carrington Y, Alber A, Ehlting J. Molecular characterization of quinate and shikimate metabolism in Populus trichocarpa. J Biol Chem. 2014;289:23846-23858.

13. Colon M, Nerín C. Synergistic, antagonistic and additive interactions of green tea polyphenols. Eur Food Res Technol. 2016;242:211-220. 